\title{
Erratum
}

\section{Erratum to "Early Diagnosis of Nonconvulsive Status Epilepticus Recurrence with Raw EEG of a Bispectral Index Monitor"}

\author{
Aristide Ntahe \\ Département d'Anesthésie-Réanimation, Hôpital Saint-Louis, Assistance Publique-Hôpitaux de Paris, 1 Avenue Claude Vellefaux, \\ 75010 Paris, France \\ Correspondence should be addressed to Aristide Ntahe; aristide.ntahe@yahoo.fr
}

Received 8 October 2018; Accepted 11 October 2018; Published 16 December 2018

Copyright (c) 2018 Aristide Ntahe. This is an open access article distributed under the Creative Commons Attribution License, which permits unrestricted use, distribution, and reproduction in any medium, provided the original work is properly cited.

In the article titled "Early Diagnosis of Nonconvulsive Status Epilepticus Recurrence with Raw EEG of a Bispectral Index Monitor" [1], additional references should have been cited, included in the text below as references 16-18 [2-4]. Accordingly, the sixth and seventh paragraphs in Discussion should read as follows:

In ICU, BIS monitors are used in different contexts: when patients have intracranial hypertension, BIS and SR values are used to titrate barbiturate treatment $[16,17]$; when patients have refractory status epilepticus, BIS and SR values are used to guide the depth of sedation if cEEG is not available because there is a strong correlation between BIS and SR values and the burst rate monitored with conventional EEG [18].

The reliability of BIS and SR values depends entirely on a good EEG signal quality, but in routine clinical practice, physicians tend to focus essentially on this two processed parameters. In the present case, neither BIS nor SR values changed markedly at the moment the real time EEG started to show seizure patterns, which means that the NCSE recurrence could have been missed or diagnosed with delay. The diagnostic value of the real time EEG of BIS monitor is high because it well diagnoses a recruiting rhythm, spikes, and spikes waves during generalized tonic-clonic seizures [15].

\section{References}

[1] Aristide Ntahe, "Early diagnosis of nonconvulsive status epilepticus recurrence with raw EEG of a bispectral index monitor," Case Reports in Critical Care, vol. 2018, Article ID 1208401, 4 pages, 2018.

[2] R. R. Riker, G. L. Fraser, and M. L. Wilkins, "Comparing the bispectral index and suppression ratio with burst suppression of the electroencephalogram during pentobarbital infusions in adult intensive care patients," Pharmacotherapy: The Journal of Human Pharmacology and Drug Therapy, vol. 23, no. 9, pp. 1087-1093, 2003.

[3] V. Cottenceau, L. Petit, F. Masson et al., "The use of bispectral index to monitor barbiturate coma in severely brain-injured patients with refractory intracranial hypertension," Anesthesia \& Analgesia, vol. 107, no. 5, pp. 1676-1682, 2008.

[4] T. Musialowicz, E. Mervaala, R. Kälviäinen, A. Uusaro, E. Ruokonen, and I. Parviainen, "Can BIS monitoring be used to assess the depth of propofol anesthesia in the treatment of refractory status epilepticus?" Epilepsia, vol. 51, no. 8, pp. 15801586, 2010. 


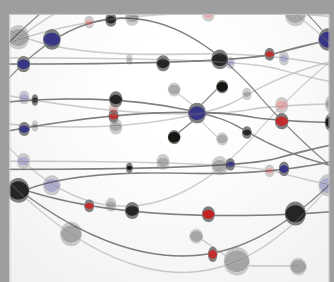

The Scientific World Journal
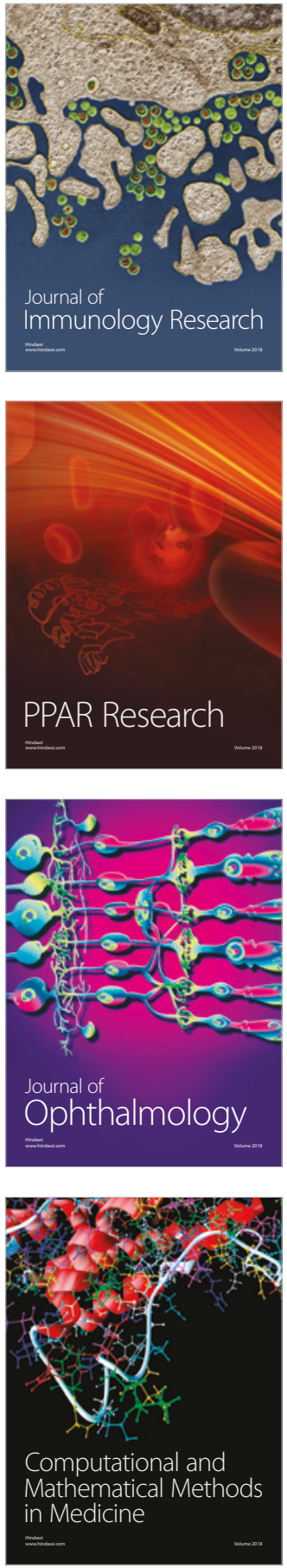

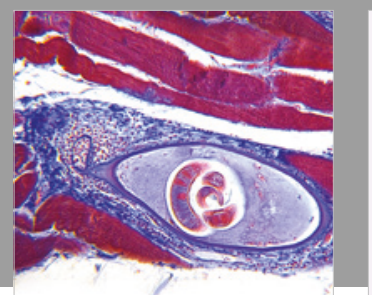

Gastroenterology Research and Practice

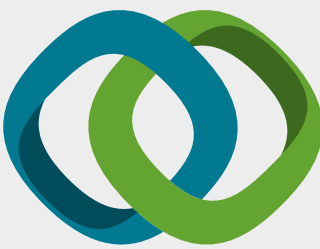

\section{Hindawi}

Submit your manuscripts at

www.hindawi.com
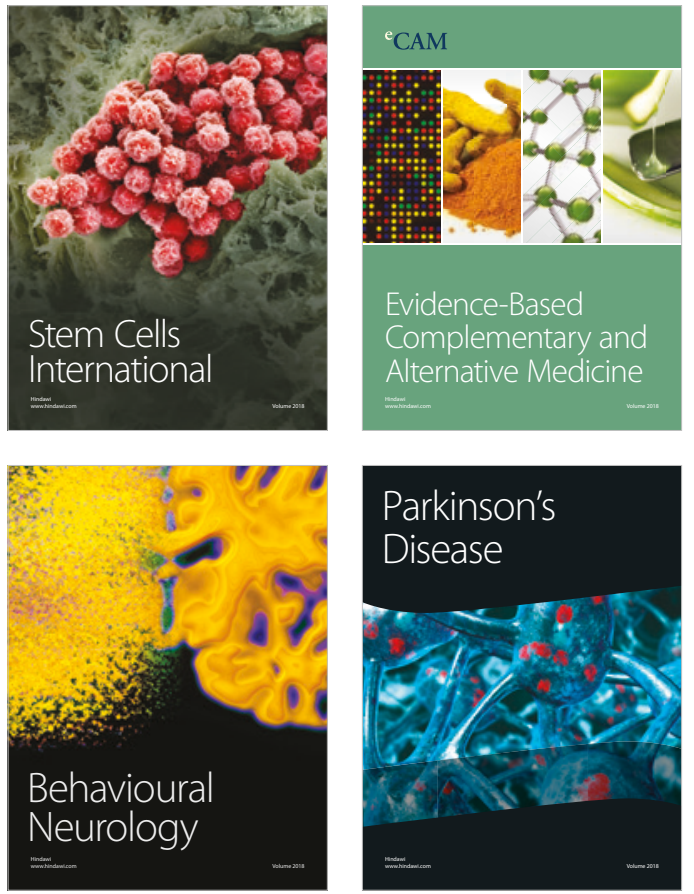

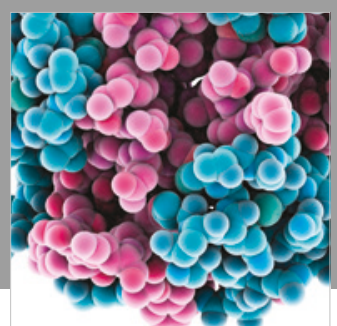

ournal of

Diabetes Research

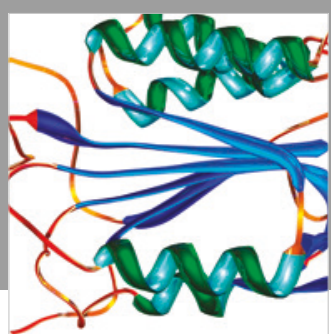

Disease Markers
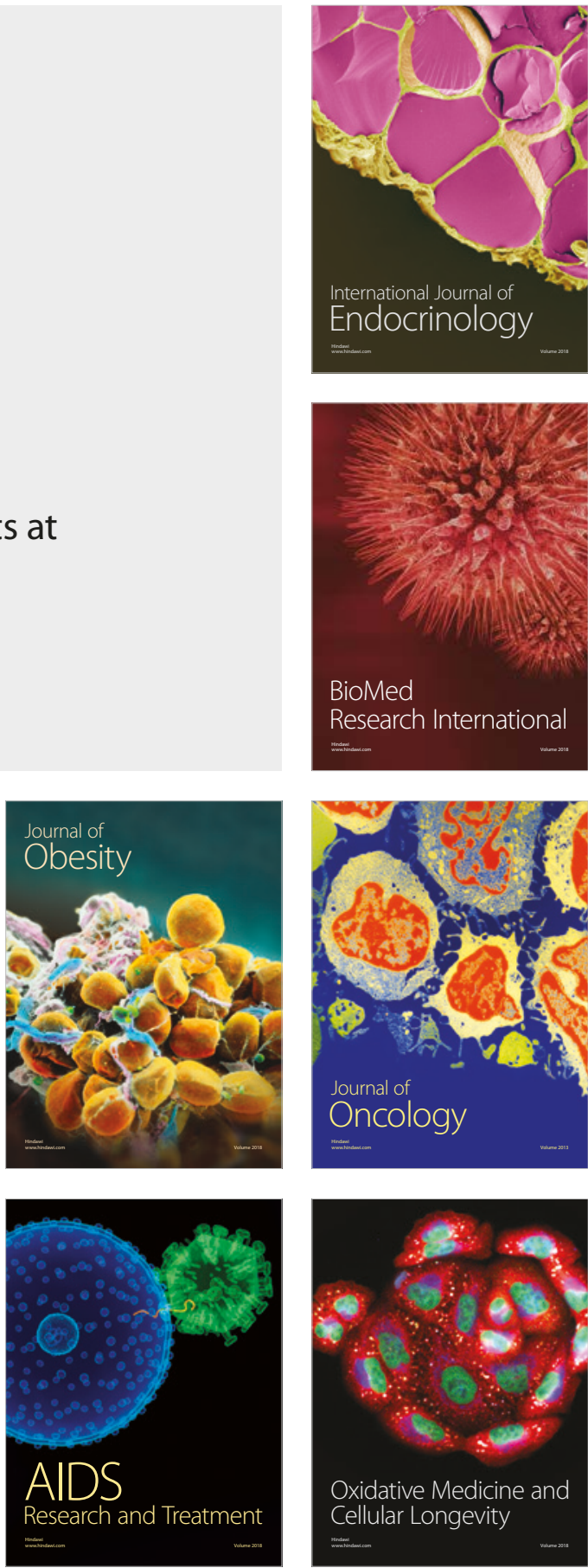